\title{
SOCIAL ENTREPRENEURSHIP AS PRACTICAL SOCIAL JUSTICE
}

\author{
THANE KREINER \\ Santa Clara University \\ Santa Clara, California, U.S.A. \\ TKreiner@scu.edu
}

The notion of a special issue devoted to social entrepreneurship arose at a July 2012 GSBI Network meeting preceding the $18^{\text {th }}$ IABJS World Forum in Barcelona. The Global Social Benefit Incubator (GSBI $\left.{ }^{\mathrm{TM}}\right)$ Network is a group of mission-aligned universities that incubate and accelerate social enterprises, or wish to. Sharing best practices and content, the group's aim is simple: help more social entrepreneurs help more people living in poverty. The GSBI Network includes Ateneo de Manila, ESADE, Javeriana, Loyola Institute of Business Administration, Santa Clara, and XLRI, as well as several of the nascent African Jesuit universities. Social enterprise incubator or accelerator programs are already in operation at some of these institutes, including ten years of GSBI experience at Santa Clara.

The GSBI originated from the observation that technology innovations benefiting humanity, such as those honored by The Tech Awards program, rarely achieved meaningful scale. The GSBI seeks to link social enterprises using these innovations to the Silicon Valley acumen of building scalable, sustainable ventures. While stories of innovations benefiting hundreds or thousands of lives are inspiring and heartwarming at black-tie events, and they certainly matter to those hundreds or thousands of people, such impact represents a tiny fraction of those suffering from the pressing problems of poverty.

On our planet with seven billion people, 1.5 billion lack access to electricity and thus are unable to read or engage in income-generating activities after night falls. Some 3 billion cook on open fires, using increasingly scarce wood and accelerating the tragic pace of deforestation. Nearly 1 billion lack access to safe drinking water, thereby repeatedly suffering from diarrheal diseases that rob their bodies and minds of 
vital nutrients. Over 2.5 billion lack access to improved sanitation: they defecate in the open, and propagate the cycle of infectious disease transmission. For 147 million children under 5 years of age, such malnutrition impairs normal brain development, permanently excluding them from many educational and livelihood opportunities. Over 750 million adults are functionally illiterate: they cannot read or write. Half a billion smallholder farmers do not have access to fair market prices for the crops they labor to produce. The list of such statistics continues ad infinitum.

While traditional paradigms to stimulate economic development have met with some success, for the most part, they have not effected systemic change among poor communities. Too much is lost along the way, and in both directions. Development agencies funnel money through governments and large NGOs; corruption and inefficiency exact enormous taxes; solutions are sometimes culturally inappropriate. Free goods and services can unintentionally create collateral economic damage by spoiling markets, and often, the environment. The needs of the poor are poorly understood, and the poor are too infrequently involved in the design of sustainable solutions. Traditional knowledge may be trumped by well-intentioned "solutions": for example, the proliferation of monoculture now appears to be causing substantial environmental damage in many geographies where permaculture technologies that were developed over millennia were supplanted.

The social entrepreneurship movement holds enormous potential to address market and government failures. Social entrepreneurs tend to engage local communities in the design and delivery of their products and services, thereby ensuring that these are appropriate for the local context. By creating local jobs, social enterprises act as nuclei for economic growth while providing goods and services that address the needs of the poor. Respect for the environment and sustainability of the planet are frequent design input requirements as well as success metrics for social enterprises.

This special issue of the Journal of Management for Global Sustainability is devoted to social entrepreneurship, with an emphasis on solutions that preserve the planet's capacity to support our own and other species. The first two articles explore the nature of social enterprises and how they promote social justice and global sustainability. The next two examine the role of technology through opposite ends of a lens: appropriate design from the user perspective, and technology contributions to scaling and poverty alleviation. A trio of contributions focuses on off-grid clean energy, a sector of particular relevance to poverty alleviation in ways that reduce the human burden on the planet. The interplay between health and sustainable agriculture continues this theme in a fourth sector- 
specific article. Finally, two articles analyze the role of human capital and of incubators and accelerators in scaling social enterprises.

But what is a social enterprise? Classic not-for-profit and for-profit paradigms are insufficient to capture the emerging diversity of social enterprise business models; the relevant dimension is social, and often environmental, impact, rather than economics. Woolley, Bruno, and Carlson examine social venture business models, evaluating the balance between economic returns and social impact in a sample size of 124 social enterprises. Their examination of institutional theory is rooted in practical questions: How do archetypes change over time? Why do some revenue models scale more successfully than others? How do the context and conditions of social issues affect the business model?

Santos examines the range of social enterprise definitions and categorizations, and adapts an integrative justice approach developed for multinational corporations serving base-of-pyramid markets. The key elements for just and fair markets that serve impoverished populations include elements of global sustainability, authenticity, co-creation of value, and representation of all stakeholders. Santos augments theory with a tool for practice: a set of meta-skills to help social entrepreneurs navigate tensions between charity and problem-solving, between social impact and financial sustainability.

Appropriate design of products and services for the poor is a vital element of successful social enterprises. The ten core competencies of frugal innovation for a more just, humane, and sustainable world are described by Banerjee and Basu, with the latter being recently described in Forbes as "changing the world" (http://www.forbes.com/sites/ devinthorpe/2013/02/14/training-for-base-of-the-pyramid-populationproving-effective-in-india/). The authors illustrate each of these competencies with an example from a successful social enterprise, in essence providing an action guide to current and future practitioners. Many of the mini case studies illuminate the use of local resources, green technologies, and minimalist designs that serve the poor while reducing burdens on ecosystem services.

Technology platforms play a significant role in product and service design as well as in the operations of social enterprises. Mobile applications afford a stunning example of platform-enabled distributed innovation: developed world consumers choose from a multitude of smartphone apps; impoverished people of the planet benefit from the delivery of goods and services such as banking, market prices, and health care information. Fisac-Garcia, et al., analyze how ICT applications drive social impact both as innovations that provide direct benefit and as instruments to improve operational efficiency of social enterprises and 
NGOs. These examples form a foundation for discerning how government and private sector investment in technology platform standards can accelerate social impact.

Author of Green Energy for a Billion Poor, Wimmer's contribution to this special issue introduces us to scalable clean energy solutions for the 1.5 billion people on the planet who are not connected to the grid. Informed by years of field experience working with Grameen Shakti, she illuminates how solar energy entrepreneurs turn rural villages into manufacturing hubs managed by women engineers. The business model is sustainable, and delivers environmentally sustainable energy to fuel these nuclei for economic growth.

Koch and Hammond explore the off-grid, clean energy opportunity, estimating that the market exceeds $\$ 1$ trillion. They identify patterns of technology and business model adaptation from a database of off-grid energy social enterprises (http://www.energymap-scu.org/). Their thoughtful analysis includes deployable technologies organized by sources of power, attractive market segments, and viable business models. The value chain analysis is of particular interest to both practitioners and investors who seek to accelerate alleviation of energy poverty while promoting environmental sustainability.

Analyzing the same off-grid energy database, Albi and Lieberman provide specific examples that illustrate the three-dimensional aspect of successful social enterprises: appropriate technology solutions, business model innovations that overcome the inherent complexity of less-developed markets, and mechanisms to address contextual factors ranging from government subsidies and tariffs to culturally-aligned community governance paradigms.

Base-of-pyramid thought leader Hammond offers a perspective on how to scale impact in health care. He first notes that modern, largescale agricultural practices are linked to malnutrition and lifelong health issues in both the developing and developed world. The link between nutrition security and sustainable agriculture thus affords a unique leverage point for development organizations. A second leverage point is safe drinking water. He observes that community-scale strategies, such as those employed by social enterprises, appear to have more potential as sustainable distribution models than centralized urban systems. Hammond advocates for investment in scalable models, linking healthcare, nutrition, and safe water.

Talent is critical to the scaling of any venture; however, as Harris and Kor describe, acquisition of appropriate human capital is particu- 
larly daunting for social enterprises. They examine how human assets affect the success of ventures, and identify specific challenges related to attraction and retention of resources in two social enterprises working on different continents. In accord with this journal's focus on practical action, they propose strategies to ameliorate these challenges.

Incubators and accelerators help social entrepreneurs develop investment-ready business plans, and most critically, achieve meaningful scale. Casanovas and Bruno revisit the definition of social enterprise and explore the role incubators and accelerators play in scaling the impact of social enterprises. Academics and practitioners alike will benefit from their ten propositions about the nascent field.

When I was asked to serve as guest editor for this special issue, I imagined a series of manuscripts that would each contribute both academic knowledge and practical insights to the burgeoning movements of social entrepreneurship and global sustainability. The authors have certainly met that reasonable expectation. I did not imagine that the manuscripts would converge to create an integrated volume far exceeding the sum of its parts. I could not have imagined that, as the authors submitted their final manuscripts, a new Pope would be elected, his chosen name of Francis a symbol for service to the poor, his first words a reminder for humanity of our collective call to such service.

So, what next? Social entrepreneurship alone cannot answer all of the needs of the poor or of the planet: governments, corporations, NGOs, and other organizations must also invest in and commit to the alleviation of global poverty in ways that sustain the planet. But social entrepreneurship is undoubtedly a vital force for change at a unique moment in history. My work as editor has further convinced me that our vision at Santa Clara to positively impact 1 billion of the world's poor by 2020 , though ambitious, is possible. We can do so by helping more social entrepreneurs achieve success and scale. GSBI Network incubators and accelerators are vital to realizing this vision and share a mission for a more just, humane, and sustainable world. Readers, whatever their vocations, might ask how their endeavors can contribute to this momentum, then intensify relevant efforts.

Social entrepreneurs are the visionaries who craft innovative business plans to serve the poor and benefit the environment; they are charismatic leaders who attract talent to implement their visions. This special issue is dedicated to them and their work, with the hope that the collective wisdom found within will accelerate progress in service to humanity and the planet. 